Tropical Journal of Pharmaceutical Research June 2021; 20 (6): 1159-1164

ISSN: $1596-5996$ (print); 1596-9827 (electronic)

(C) Pharmacotherapy Group, Faculty of Pharmacy, University of Benin, Benin City, 300001 Nigeria.

Available online at http://www.tjpr.org

Original Research Article

http://dx.doi.org/10.4314/tjpr.v20i6.9

\title{
Ruscogenin protects against cisplatin-induced apoptosis, inflammation, and oxidative stress of renal tubular epithelial cells
}

\author{
Yean Yu${ }^{1}$, Baohong Feng ${ }^{1}$, Li Yan ${ }^{2}$, Zhimin Bi ${ }^{1}$, Geli Zhu ${ }^{1}$, Fen Jiang ${ }^{3 *}$ \\ ${ }^{1}$ Department of Nephrology, ${ }^{2}$ Department of Respiratory, Wuhan Third Hospital, Tongren Hospital of Wuhan University, Wuhan \\ City, Hubei Province 430060, ${ }^{3}$ Department of Nephrology, The first Affiliated Hospital of the University of South China, \\ Hengyang City, Hunan Province 421000, China
}

*For correspondence: Email: jiangfen202102@163.com; Tel: +86-0734-8578702

Sent for review: 3 March 2021

Revised accepted: 27 May 2021

\begin{abstract}
Purpose: To determine the potential effect of ruscogenin in cisplatin-induced nephrotoxicity. Methods: Rat renal tubular epithelial cells (NRK-52E) were treated with $50 \mu \mathrm{M}$ cisplatin to establish an in vitro cell model of nephrotoxicity. Cytotoxicity was assessed by MTT (3-(4,5-dimethylthiazol-2-yl)-2,5diphenyltetrazolium bromide) assay, flow cytometry, and western blot. Different concentrations of ruscogenin $(2.5,5$, and $10 \mu \mathrm{M})$ were incubated with cisplatin-treated NRK-52E cells. Alterations in the nod-like receptor family, the pyrin domain-containing protein (NLRP3) inflammasome, toll-like receptor 4 (TLR4)/nuclear factor kappa B (NF-kB), and nuclear factor erythropoietin-2-related factor 2 (Nrf2)/heme oxygenase $1(\mathrm{HO}-1)$ components were determined using western blot. Flow cytometry was also used to investigate the levels of reactive oxygen species (ROS).

Results: Ruscogenin significantly increased cell viability $(p<0.01)$ and suppressed apoptosis of NRK$52 E$ cells $(p<0.01)$, attenuating cisplatin-induced cytotoxicity. The NLRP3 inflammasome was activated in cisplatin-treated NRK-52E cells with enhanced NLRP3, interleukin 1 beta, and cleaved caspase-1; however, ruscogenin significantly decreased the expression of NLRP3 inflammasome components ( $p<$ 0.01). Ruscogenin attenuated cisplatin-induced expression of TLR4, myeloid differentiation primary response 88, and NF-KB. Further, cisplatin induction enhanced ROS formation, with increased malondialdehyde and decreased glutathione reductase and catalase levels. Ruscogenin attenuated cisplatin-induced ROS accumulation in NRK-52E cells through up-regulation of Nrf2 and HO-1.

Conclusion: Ruscogenin protects against cisplatin-induced apoptosis, inflammation, and oxidative stress in renal tubular epithelial cells via suppression of TLR4/NF-KB activation and promotion of Nrf2/HO-1 activation. Therefore, ruscogenin provides a potential therapeutic strategy for mitigating cisplatin-induced nephrotoxicity.
\end{abstract}

Keywords: Ruscogenin, Cisplatin, Apoptosis, Inflammation, Oxidative stress, Renal tubular epithelial cells, TLR4/NF-KB, Nrf2/HO-1

This is an Open Access article that uses a fund-ing model which does not charge readers or their institutions for access and distributed under the terms of the Creative Commons Attribution License (http://creativecommons.org/licenses/by/4.0) and the Budapest Open Access Initiative (http://www.budapestopenaccessinitiative.org/read), which permit unrestricted use, distribution, and reproduction in any medium, provided the original work is properly credited.

Tropical Journal of Pharmaceutical Research is indexed by Science Citation Index (SciSearch), Scopus, International Pharmaceutical Abstract, Chemical Abstracts, Embase, Index Copernicus, EBSCO, African Index Medicus, JournalSeek, Journal Citation Reports/Science Edition, Directory of Open Access Journals (DOAJ), African Journal Online, Bioline International, Open-J-Gate and Pharmacy Abstracts

\section{INTRODUCTION}

Acute kidney injury, characterized by a loss of kidney function, is a common complication in hospitalized patients [1]. The incidence, as well as the morbidity and mortality, of acute kidney injury has been increasing rapidly in the elderly [2]. Although the etiology of acute kidney injury is 
complicated, sepsis, ischemic reperfusion, and nephrotoxic drugs are considered to be pathogenic factors of acute kidney injury [3].

Cisplatin, a well-known anti-tumor drug, has been widely used in solid and hematologic tumors [4]. However, the side effects of cisplatin, such as nephrotoxicity, limits clinical application [5]. About one third of patients show renal dysfunction symptoms after cisplatin treatment [5]. Cisplatin treatment induces proximal tubular epithelial cell apoptosis, inflammation, and oxidative stress to aggravate the renal injury [6].

Ruscogenin was first isolated from Ruscus aculeatus and is an effective steroid sapogenin in traditional Chinese medicine [7]. Lipopolysaccharide-induced cell apoptosis of pulmonary endothelial cells is repressed by ruscogenin [8]. Ruscogenin exerts antiinflammatory effects against lipopolysaccharideinduced acute lung injury [9]. Streptozotocininduced diabetic nephropathy is ameliorated by ruscogenin [10]. However, the effect of ruscogenin on cisplatin-induced acute kidney injury has not been reported.

The protective effect of ruscogenin on cisplatintreated rat renal proximal tubular epithelial cells (NRK-52E) was assessed. Inflammation, cell apoptosis, oxidative stress, as well as the underlying mechanisms, were also investigated in this study.

\section{EXPERIMENTAL}

\section{Cell culture and treatment}

Rat renal proximal tubular epithelial cells (NRK52E), purchased from FMG-Bio (Sciencell, Shanghai, China), were cultured in DMEM containing $10 \%$ fetal bovine serum (Gibco BRL, Grand Island, NY, USA) in a $37^{\circ} \mathrm{C}$ humidified incubator. Cells were divided into 5 groups: control, cisplatin-treated NRK-52E cells, cisplatin-treated NRK-52E cells with $2.5 \mu \mathrm{M}$ ruscogenin, cisplatin-treated NRK-52E cells with $5 \mu \mathrm{M}$ ruscogenin, and cisplatin-treated NRK-52E cells with $10 \mu \mathrm{M}$ ruscogenin. The control cells were incubated with phosphate buffered saline. Cells in the cisplatin groups were incubated with $50 \mu \mathrm{M}$ cisplatin (Sigma-Aldrich, St. Louis, MO, USA) for $24 \mathrm{~h}$. Cells in the ruscogenin groups were incubated with different concentrations of ruscogenin (Sigma-Aldrich) for $24 \mathrm{~h}$.

\section{Cell viability and apoptosis}

Rat renal proximal tubular epithelial cells (NRK$52 E$ ) were plated in a 96-well plate and incubated with cisplatin and/or ruscogenin for 24 h. MTT (3-(4,5-Dimethylthiazol-2-yl)-2,5Diphenyltetrazolium Bromide) solution $(10 \mu \mathrm{L}, 5$ $\mathrm{mg} / \mathrm{mL}$; Sigma-Aldrich) was added to each well, and the cells were incubated for $4 \mathrm{~h}$. The supernatants were removed, and the cells were incubated with $150 \mu \mathrm{L}$ dimethyl sulfoxide (SigmaAldrich). Absorbance at $570 \mathrm{~nm}$ was measured with a Spectrophotometer (Thermo Fisher Scientific, Waltham, MA, USA). For cell apoptosis, NRK-52E cells were harvested and suspended in $100 \mu \mathrm{L}$ Annexin V-binding buffer (Thermo Fisher Scientific). The cells were then incubated with $5 \mu \mathrm{L}$ of Annexin V-FITC (Thermo Fisher Scientific) and $2 \mu \mathrm{L}$ of propidium iodide solution (2 $\mathrm{mg} / \mathrm{mL}$ ) in Annexin V-binding buffer. Cell apoptosis in NRK-52E cells was assessed using an Attune ${ }^{\mathrm{TM}}$ Flow Cytometer (Thermo Fisher Scientific).

\section{Reactive oxygen species (ROS) measurement}

NRK-52E cells, after cisplatin and/or ruscogenin treatment, were harvested and suspended in 100 $\mu \mathrm{L}$ serum-free medium with $10 \mu \mathrm{M}$ DCFH-DA (Cellular ROS Assay Kit; Abcam, Cambridge, MA, USA) for $30 \mathrm{~min}$. Cells were then analyzed by an Attune ${ }^{\mathrm{TM}}$ Flow Cytometer.

\section{Enzyme-linked immunosorbent assay (ELISA)}

The culture medium from NRK-52E cells treated with cisplatin and/or ruscogenin was collected. Commercial ELISA kits (Thermo Fisher Scientific) were used for the determination of glutathione reductase (GSH), malondialdehyde (MDA), and catalase (CAT), following the manufacturer's instructions.

\section{Western blot}

Proteins from NRK-52E cells treated with cisplatin and/or ruscogenin were extracted using RIPA Lysis and Extraction Buffer (Thermo Fisher Scientific), and protein concentrations were quantified via an acid protein kit (Thermo Fisher Scientific). The protein samples were separated with SDS-PAGE and electro-transferred onto a polyvinylidene fluoride membrane (Millipore, Bedford, MA, USA). Bovine serum albumin (5\%; Sigma-Aldrich) was used to block the membranes; and primary antibodies were used to probe the membranes overnight at $4^{\circ} \mathrm{C}$ : antiBax and anti-Bcl-2 (1:2500, Abcam); anticaspase-1, anti-cleaved caspase-3, and anticleaved caspase-1 (1:3000, Abcam); anti-NLRP3 and anti-IL-1 $\beta$ (1:3500, Abcam); anti-TLR4, antiMYD88, and anti-NF-kB (1:4000, Abcam); antiNrf2, anti-HO-1, and anti- $\beta$-actin $(1: 4500$, Abcam). The membranes were then probed with 
horseradish peroxidase-labeled secondary antibody (1:5000; Cell Signaling, Danvers, MA, USA), and the immunoreactivities were measured using enhanced chemiluminescence (KeyGen, Nanjin, China).

\section{Statistical analysis}

Data was expressed as mean \pm standard error of the mean and analyzed with one-way analysis of variance or student's t test with GraphPad Prism software. A $p$ value less than 0.05 was considered as statistically significant.

\section{RESULTS}

\section{Ruscogenin alleviated cisplatin-induced cytotoxicity in renal tubular epithelial cells}

To establish an in vitro cell model of nephrotoxicity, rat renal tubular epithelial cells (NRK-52E) were treated with $50 \mu \mathrm{M}$ cisplatin. Cell viability of NRK-52E cells was decreased by cisplatin (Figure 1A), and apoptosis was promoted by cisplatin (Figure 1B). Incubation with ruscogenin attenuated the decreased cell viability (Figure $1 \mathrm{~A}$ ) and increased cell apoptosis (Figure $1 \mathrm{~B}$ ) in cisplatin-treated NRK-52E cells. Moreover, the cisplatin-induced reduction of $\mathrm{Bcl}-$ 2 and enhancement of Bax, as well as the increased expression of cleaved caspase-3 protein, in NRK-52E cells were reversed by ruscogenin (Figure $1 \mathrm{C}$ ), suggesting that ruscogenin exerts an anti-apoptotic effect on cisplatin-treated renal tubular epithelial cells.
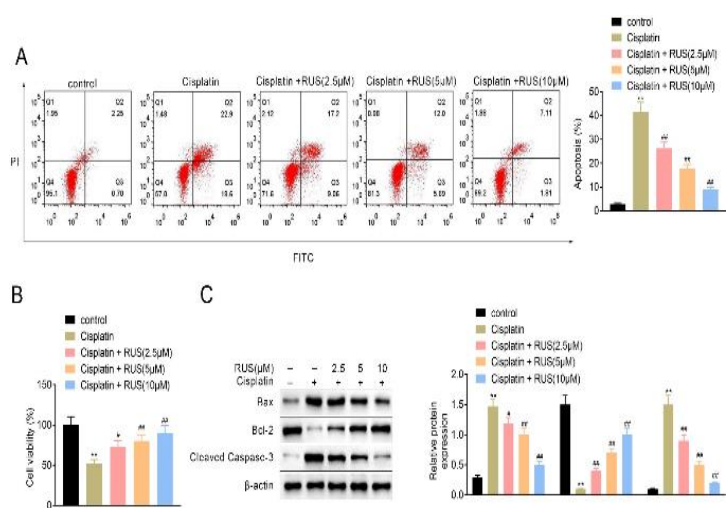

Figure 1: Ruscogenin alleviated cisplatin-induced cytotoxicity in renal tubular epithelial cells. (A) Ruscogenin (RUS) attenuated the decrease of cell viability induced by cisplatin in NRK-52E cells. (B) Ruscogenin attenuated the increase of cell apoptosis in NRK-52E cells induced by cisplatin. (C) Ruscogenin attenuated the decrease of Bcl-2, increase of Bax, and expression of cleaved caspase- 3 in NRK-52E cells induced by cisplatin. ${ }^{* *}$ cisplatin vs. control $p<0.01$. \#, \#\# cisplatin + RUS vs. cisplatin $p<0.05, p<0.01$, respectively
Ruscogenin alleviated cisplatin-induced pyrin domain-containing protein inflammasome activation in renal tubular epithelial cells

Cisplatin-induced inflammation in renal tubular epithelial cells was evaluated using analysis of pyrin domain-containing protein (NLRP3) inflammasome components. Results showed that the NLRP3 inflammasome was promoted by cisplatin in NRK-52E cells with increased NLRP3, interleukin 1 beta (IL-1 $\beta$ ), and cleaved caspase-1 (Figure 2). Moreover, ruscogenin showed an anti-inflammatory effect on cisplatintreated renal tubular epithelial cells through a dose-dependent reduction of NLRP3, IL-1 $\beta$, and cleaved caspase-1 (Figure 2).

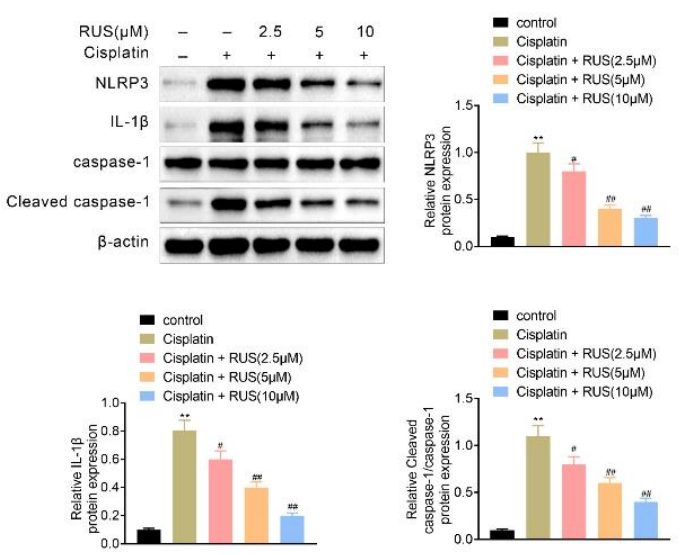

Figure 2: Ruscogenin alleviated cisplatin-induced NLRP3 inflammasome activation in renal tubular epithelial cells. Ruscogenin (RUS) attenuated cisplatin-induced increases of NLRP3, IL-1 $\beta$, and cleaved caspase-1 in NRK-52E cells. ${ }^{* *}$ cisplatin vs. control $p<0.01$. \#, \#\# cisplatin + RUS vs. cisplatin $p<$ $0.05, p<0.01$, respectively

Ruscogenin mediated TLR4/MYD88/NF-KB pathway in cisplatin-treated renal tubular epithelial cells

The underlying mechanism involved in the antiinflammatory effect of ruscogenin was investigated. Protein expression of toll-like receptor 4 (TLR4), myeloid differentiation primary response 88 (MYD88), and nuclear factor kappa $B$ (NF-kB) was up-regulated in cisplatin-treated NRK-52E cells (Figure 3). However, ruscogenin suppressed activation of the TLR4/MYD88/NFKB pathway, as indicated by a decrease in TLR4, MYD88, and NF-KB protein expression (Figure 3). Thus, the anti-inflammatory effect of ruscogenin in cisplatin-treated renal tubular epithelial cells might be mediated by the TLR4/MYD88/NF-kB pathway. 

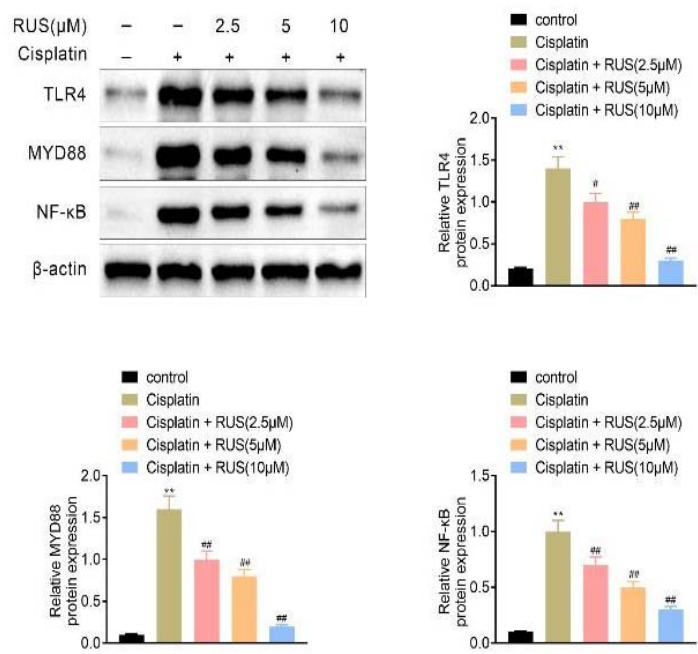

Figure 3: Ruscogenin mediated TLR4/MYD88/NF-KB pathway in cisplatin-treated renal tubular epithelial cells. Ruscogenin (RUS) attenuated cisplatin-induced increases in TLR4, MYD88 and NF-KB expression in NRK-52E cells. ${ }^{* *}$ cisplatin vs. control $p<0.01$. \#, \#\# cisplatin + RUS vs. cisplatin $p<0.05, p<0.01$, respectively

\section{Ruscogenin alleviated cisplatin-induced oxidative stress in renal tubular epithelial cells}

In addition to apoptosis and inflammation, oxidative stress in cisplatin-treated NRK-52E cells was evaluated. Cisplatin induced oxidative damage in NRK-52E cells through an increase of MDA and a decrease of GSH and CAT (Figure 4 A). However, ruscogenin treatment dosedependently reversed the effects of cisplatin on GSH, MDA, and CAT levels in NRK-52E cells (Figure $4 \mathrm{~A}$ ). Ruscogenin attenuated cisplatininduced intracellular ROS accumulation in NRK52E cells (Figure $4 \mathrm{~B}$ ), indicating that ruscogenin has an anti-oxidant effect on cisplatin-treated renal tubular epithelial cells.

\section{Ruscogenin mediated Nrf2/HO-1 pathway in cisplatin-treated renal tubular epithelial cells}

The underlying mechanism involved in the antioxidant effect of ruscogenin was investigated. Protein expression of nuclear factor erythropoietin-2-related factor 2 (Nrf2) and heme oxygenase 1 (HO-1) were down-regulated in cisplatin-treated NRK-52E cells (Figure 5). However, ruscogenin enhanced protein expression of Nrf2 and $\mathrm{HO}-1$ (Figure 5), suggesting that the anti-oxidant effect of ruscogenin in cisplatin-treated renal tubular epithelial cells is mediated by the $\mathrm{Nrf} 2 / \mathrm{HO}-1$ pathway.
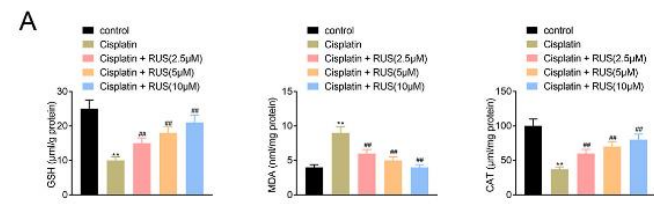

B

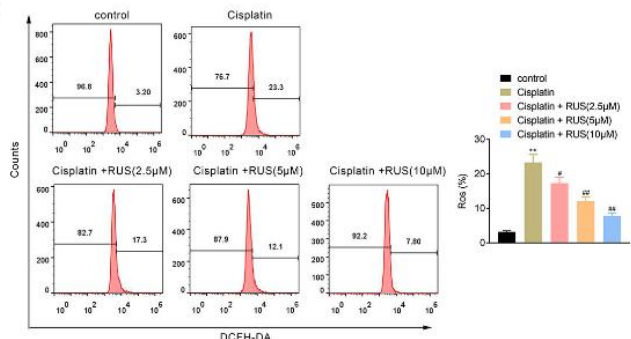

Figure 4: Ruscogenin alleviated cisplatin-induced oxidative stress in renal tubular epithelial cells. (A) Ruscogenin (RUS) attenuated the cisplatin-induced increase of MDA and decrease of GSH and CAT in NRK-52E cells. (B) Ruscogenin attenuated the cisplatin-induced increase of ROS in NRK-52E cells. ** vs. control $p<0.01$. \#, \#\# vs. cisplatin $p<0.05, p<$ 0.01 , respectively
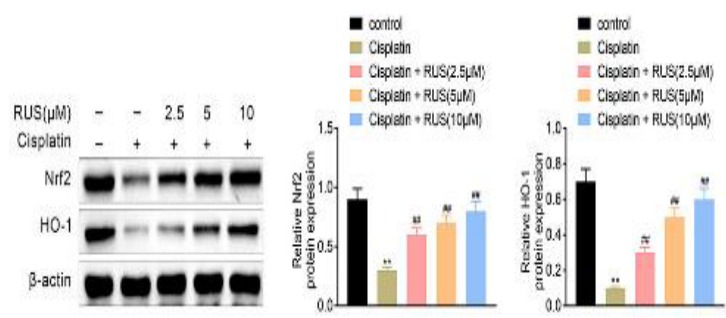

Figure 5: Ruscogenin mediated $\mathrm{Nrf} 2 / \mathrm{HO}-1$ pathway in cisplatin-treated renal tubular epithelial cells. Ruscogenin (RUS) attenuated the cisplatin-induced decrease of Nrf2 and $\mathrm{HO}-1$ in NRK-52E cells. ** cisplatin vs. control $p<0.01$. \#\# cisplatin + RUS vs. cisplatin $p<0.01$

\section{DISCUSSION}

Cisplatin generally accumulates in renal tubular epithelial cells, and the concentration is five times higher than in the blood [11]. Therefore, cisplatin induces tubular epithelial cell cytotoxicity with DNA damage, apoptosis, and inflammation, thus evoking renal dysfunction [11]. Nephrotoxicity induced by cisplatin is a common complication in the clinical use of cisplatin [11]. Renal dysfunction in diabetic rats reportedly has been reversed by ruscogenin treatment [10]. Thus, the protective effect of ruscogenin against cisplatin-induced nephrotoxicity was investigated in this study.

Cisplatin-induced nephrotoxicity is accompanied by apoptosis of renal tubular epithelial cells, and suppression of renal tubular epithelial cell apoptosis reduces nephrotoxicity [12]. A previous 
study showed that ruscogenin represses lipopolysaccharide-induced apoptosis of pulmonary endothelial cells [8]. This study showed that ruscogenin attenuated the cisplatininduced decrease of cell viability and increase of cell apoptosis in NRK-52E cells, suggesting that ruscogenin has an anti-apoptotic effect on cisplatin-treated renal tubular epithelial cells.

Cisplatin stimulates infiltration of inflammatory cells that enhance levels of pro-inflammatory cytokines in the renal tissues, and renal inflammation is a characteristic feature of cisplatin-induced acute kidney injury [13]. Nephrotoxicity induced by cisplatin is related to activation of the NLRP3 inflammasome, and inhibition of the NLRP3 inflammasome attenuated renal fibrosis induced by cisplatin [14]. Ruscogenin suppresses activation of the NLRP3 inflammasome to attenuate cerebral ischemia-induced damage of the blood-brain barrier [15]. In this study, expression of NLRP3, IL-1 $\beta$, and cleaved caspase-1 in NRK-52E cells was reduced by ruscogenin, suggesting an antiinflammatory effect of ruscogenin on cisplatintreated renal tubular epithelial cells. However, the effect of ruscogenin on secretion of proinflammatory cytokines in cisplatin-treated renal tubular epithelial cells should be investigated in further research.

The activity of the NLRP3 inflammasome has been shown to be driven by NF-KB during progression of chronic kidney disease [16]. Suppression of TLR4/NF-kB/NLRP3 inhibited the inflammatory response induced by cisplatin and alleviated renal injury [17]. The suppressive effect of ruscogenin on TLR4/NF-KB has been reported before $[8,10,15]$. Protein expression of TLR4, MYD88, and NF-KB in NRK-52E cells was reduced by ruscogenin, suggesting that ruscogenin has an anti-inflammatory effect of on cisplatin-treated renal tubular epithelial cells through inactivation of the TLR4/NF-KB/NLRP3 pathway.

In addition to inflammation, oxidative stress is considered to be another characteristic feature of cisplatin-induced acute kidney injury [18]. Oxidative stress leads to renal tubular epithelial cell toxicity due to accumulation of ROS that activates death signaling [18]. Antioxidants, such as vitamin $\mathrm{E}$, vitamin $\mathrm{C}$, and resveratrol, have been widely used for the prevention of cisplatininduced nephrotoxicity [18]. Generation of ROS by oxygen-glucose deprivation/reperfusion has been suppressed by ruscogenin in bEnd.3 cells [15]. Oxidative damage in NRK-52E cells was induced by cisplatin through increases in MDA and ROS, as well as reductions of GSH and
CAT. However, ruscogenin suppressed oxidative stress and intracellular ROS accumulation, suggesting an anti-oxidant effect on cisplatintreated renal tubular epithelial cells. Ruscogenin, in this study, attenuated cisplatin-induced reductions of $\mathrm{Nrf} 2$ and $\mathrm{HO}-1$, thus ameliorating oxidative stress.

In general, ruscogenin alleviated cisplatininduced injury in renal tubular epithelial cells through anti-inflammatory and anti-oxidant capacities. The TLR4/NF-KB/NLRP3 and Nrf2/HO-1 pathways might be responsible for the anti-inflammatory and anti-oxidant capacities, respectively. However, the in vivo role of ruscogenin on renal function should be investigated to further confirm the protective role against cisplatin-induced nephrotoxicity.

\section{DECLARATIONS}

\section{Conflict of interest}

No conflict of interest is associated with this work.

\section{Contribution of authors}

We declare that this work was done by the authors named in this article and all liabilities pertaining to claims relating to the content of this article will be borne by the authors. Yean Yu and Baohong Feng designed the study and supervised the data collection, Li Yan analyzed the data, Zhimin Bi interpreted the data, and Geli Zhu and Fen Jiang prepared the manuscript for publication and reviewed the draft of the manuscript. All authors have read and approved the manuscript.

\section{Open Access}

This is an Open Access article that uses a funding model which does not charge readers or their institutions for access and distributed under the terms of the Creative Commons Attribution License (http://creativecommons.org/licenses/by/ 4.0) and the Budapest Open Access Initiative (http://www.budapestopenaccessinitiative.org/rea d), which permit unrestricted use, distribution, and reproduction in any medium, provided the original work is properly credited.

\section{REFERENCES}

1. Ronco C, Bellomo R, Kellum JA. Acute kidney injury. Lancet 2019; 394(10212): 1949-1964.

Trop J Pharm Res, June 2021; 20(6): 1163 
2. Challiner $R$, Ritchie JP, Fullwood $C$, Loughnan $P$, Hutchison AJ. Incidence and consequence of acute kidney injury in unselected emergency admissions to a large acute UK hospital trust. BMC Nephrol 2014; 15(1): 84.

3. Vincent IS, Okusa MD. Adenosine $2 A$ receptors in acute kidney injury. Acta physiol 2015; 214(3): 303-310.

4. Dasari S, Bernard Tchounwou P. Cisplatin in cancer therapy: Molecular mechanisms of action. Eur $J$ Pharmacol 2014; 740: 364-378.

5. Palipoch S, Punsawad C, Chinnapun D, Prasit. Amelioration of Cisplatin-Induced Nephrotoxicity in Rats by Curcumin and $\alpha$-Tocopherol. Trop J Pharm Res 2013; 12(6): 973-979

6. Santos N, Rodrigues M, Martins N, Santos A. Cisplatininduced nephrotoxicity and targets of nephroprotection: An update. Arch Toxicol 2012; 86: 1233-1250.

7. Khojasteh A, Sanchez-Muñoz R, Moyano E, Bonfill M, Cusido RM, Eibl R, Palazon J. Biotechnological production of ruscogenins in plant cell and organ cultures of Ruscus aculeatus. Plant Physiol Bioch 2019; 141: 133-141.

8. Wu Y, Wang Y, Gong S, Tang J, Zhang J, Li F, Yu B, Zhang $Y$, Kou J. Ruscogenin alleviates LPS-induced pulmonary endothelial cell apoptosis by suppressing TLR4 signaling. Biomed Pharmacother 2020; 125: 109868.

9. Sun Q, Chen L, Gao M, Jiang W, Shao F, Li J, Wang J, Kou J, Yu B. Ruscogenin inhibits lipopolysaccharideinduced acute lung injury in mice: Involvement of tissue factor, inducible NO synthase and nuclear factor (NF)KB. Int Immunopharmacol 2012; 12(1): 88-93.

10. Lu H-J, Tzeng T-F, Liou S-S, Da Lin S, Wu M-C, Liu IM. Ruscogenin ameliorates diabetic nephropathy by its anti-inflammatory and anti-fibrotic effects in streptozotocin-induced diabetic rat. BMC Complem Altern M 2014; 14(1): 110.

11. Camano S, Lazaro A, Moreno-Gordaliza E, Torres A, de Lucas C, Humanes B, Lazaro J, Gomez-Gomez M,
Boscá L, Tejedor A. Cilastatin Attenuates CisplatinInduced Proximal Tubular Cell Damage. J Pharmacol Exp Ther 2010; 334: 419-429.

12. Zhu $H$, Jiang $W$, Zhao $H$, He $C$, Tang $X, X u S, X u C$, Feng $R, L i J$, Ma $T$ et al. PSTPIP2 inhibits cisplatininduced acute kidney injury by suppressing apoptosis of renal tubular epithelial cells. Cell Death Dis 2020; 11(12): 1057.

13. Yang $C$, Guo $Y$, Huang $T$-s, Zhao J, Huang $X$-J, Tang $H$ $x$, An N, Pan Q, Xu Y-z, Liu H-f. Asiatic acid protects against cisplatin-induced acute kidney injury via antiapoptosis and anti-inflammation. Biomed Pharmacother 2018; 107: 1354-1362.

14. Li S, Lin Q, Shao X, Mou S, Gu L, Wang L, Zhang Z, Shen J, Zhou Y, Qi $C$ et al. NLRP3 inflammasome inhibition attenuates cisplatin-induced renal fibrosis by decreasing oxidative stress and inflammation. Exp Cell Res 2019; 383(1): 111488.

15. Cao G, Jiang N, Hu Y, Zhang $Y$, Wang G, Yin M, Ma X, Zhou K, Qi J, Yu B et al. Ruscogenin Attenuates Cerebral Ischemia-Induced Blood-Brain Barrier Dysfunction by Suppressing TXNIP/NLRP3 Inflammasome Activation and the MAPK Pathway. Int $J$ Mol Sci 2016; 17(9): 1418.

16. Foresto-Neto O, Ávila VF, Arias SCA, Zambom FFF, Rempel LCT, Faustino VD, Machado FG, Malheiros DMAC, Abensur H, Camara NOS et al. NLRP3 inflammasome inhibition ameliorates tubulointerstitial injury in the remnant kidney model. Lab Invest 2018; 98(6): 773-782.

17. Gao H, Wang X, Qu X, Zhai J, Tao L, Zhang Y, Song Y, Zhang $W$. Omeprazole attenuates cisplatin-induced kidney injury through suppression of the TLR4/NFKB/NLRP3 signaling pathway. Toxicology 2020; 440: 152487.

18. Rodrigues M, Gobe G, Santos N, Santos A. Carvedilol Protects Against Apoptotic Cell Death Induced by Cisplatin in Renal Tubular Epithelial Cells. J Toxicol Env Heal A 2012; 75: 981-990. 